\title{
Sharing Impressions: An investigation about participatory museums and UX design
}

\author{
Aila Regina da Silva \\ University of Sao Paulo \\ Prof. Mello Moraes Avenue, Travessa 8, Butantã, \\ São Paulo, SP, Brazil \\ aila.regina@usp.br
}

\author{
Gabriele Mauany Ferreira Alencar \\ Unaffiliated \\ East London \\ London, UK \\ mauany.alencar@gmail.com
}

\begin{abstract}
This investigation arises from the authors' experiences working as museums' front of house staff and mediator, observing visitors and their challenges to engage with the artwork horizontally. Our investigation concentrates its efforts on identifying a common denominator among an audience in The UK and Sao Paulo (Brazil) by testing an approach based on audio. Crossing the participatory museums studies, our experience working in museums and UX Design tools, this paper shows the research process to develop a solution for a collaborative audio tool. It shows an effective way to build a connection with the artwork by giving to the audience a tool to make the fruition of art independent and horizontally.
\end{abstract}

Museal Processes. UX Design. Audio guide. Identity. Index.

\section{INTRODUCTION}

The Brazilian museologist Waldisa Rússio (19351990) left a legacy unveiling new horizons in museological actions, anchoring paths as accessibility, knowledge of multiple cultural heritages and empathy to the problems of the museum's audience. Rússio (Carvalho \& Escudero 2020) understood that the scenario of the museum is as important as the art itself to create an atmosphere that embraces the audience. As a scenario we conceive all the interactions between a person and the artwork, as the architecture, the expography, the communication of the exhibition, the ambience provided, the curatorial text, and the digital developments, as virtual exhibitions, as examples.

Museums have expanded beyond the space within their walls, having online spaces, such as websites and social media, as an augmented place in which visitors can also navigate remotely or during a physical visit. However, due to the widespread isolation in most parts of the globe caused by the coronavirus pandemic, visitors had to rely nearly exclusively on the sphere of online exploration. The same affected the authors, which informed this search in understanding how participatory tools mediated by digital technologies could help us to view artwork through the online screen and still make it accessible, facilitating the fruition of art and the participation of the audience.
Museums are miscellaneous. They have to deal with their collection throughout the years and establish a mediation with the audience in order to contextualise the artwork within the society and zeitgeist. As a heterogeneous space, museums include different styles and collections - regardless if it's Ancient or Contemporary Art - that constantly need a reconfiguration to adapt to the society, in order to guarantee access and democratization of the Art.

In contemporary life, creating more participatory opportunities within museum settings to engage and draw the audience closer to the artefacts and artwork has been the goal of many institutions. However, according to Nina Simon (2010), those attempts may not be as successful as envisioned due to the public's resistance or ineptitude to perform the proposed task, especially when not mediated by another person, but by technological artefacts. Moreover, pursuing participation means understanding that this concept changes depending on the person, as Jenkins affirms, "not every member must contribute, but all must believe they are free to contribute when ready and that what they contribute will be appropriately valued." (Jenkins 2009, pp. 7)

The original idea that prompted this investigation came from the curiosity of merging the authors' experience as museum mediators and front of house staff, combined with the user experience design background shared by both. The intent was 
to design a tool that could be used either in the online or onsite museal spaces, that was collaborative, horizontal and participatory in nature, but also participatory in its design process.

Along with these statements, coupled with the new pandemic world situation that has been changing the way people build a relation with art institutions, we started researching technological approaches using UX Design tools.

Using a CSD Matrix tool (Certainties, Suppositions and Doubt Matrix) as bottom line, we identified opportunities to research audio as a tool in museums:

(i) Traditional audio guides can lead to antisocial museum experiences;

(ii) Brazilian audiences are familiar and comfortable with audio messages, due to the widespread use of the whatsapp app;

(iii) Audio is democratic;

(iv) Audio can help people who don't feel comfortable with museum vocabulary.

\section{AUDIO NOT AS A GUIDE, BUT A BRIDGE}

The fruition of art using the mediation of an audio guide in museums has been experimented with since the 1950s, being first introduced by the Stedelijk Museum in Amsterdam. Today, we can easily find examples in MoMA (USA), Victoria and Albert Museum (UK) and Museum of Modern Art of Sao Paulo (Brazil). The developers back then envisioned a tool that would offer a personal and content rich experience, and "suited learning styles not served by catalogue, text panel, or label" (Tallon 2008, pp. xiii) but they were not successful due to technological limitations of the time. Nevertheless, audio guides in many different interactions and technological approaches have been developed by museal institutions over the decades.

Audio is a medium has also permeated the contemporary life, with the rise and increasing popularity of podcasts, but also as means of communication. In Brazil, the habit of communicating via audio messages is very common among the population, so common that schools and academics have tried to develop educational tools within WhatsApp as a result of the acceptance amongst the people (Schindler et al 2020).

From this background, the use of audio guides and the research of mediation in the museums that are already incorporated, the popularity of podcasts and the acceptance of audio messages by the Brazilian population, we started conceptualizing and audio tool, whilst trying to investigate if involving the public in the design process would make said tool more usable and attractive to the user-visitors.

It was also our goal to understand the role of the visitors' identities in the process of participation and selection of the content to create and to listen to. For this we used John Falk's work (2016), that states that museum visits are motivated by the visitors assumed identity at the time of the visit. Falk encapsulated those identities in 5 categories: explorer, facilitator, experience seeker, professional/hobbyist and recharger.

We started the investigation trying to understand the User Journey of museum possible visitors crossing this information, searching for data that is extensively researched by the museums and successful cases.

We used the data that ICOFOM-Brazil produced online in 2020 Data to flow through uncertainty: Part II - Results of the research with the museum audience (Dados para navegar em meio às incertezas: Parte II - resultados da pesquisa com públicos de museu) where we could extract that the audience sees the museum first as place to acquire knowledge, secondly as place to reflect about past and future. From the PhD thesis Communication of the five senses in Brazilian cultural space: strategies of mediation and accessibility for people with their differences (Sarraf 2013) we could extract methods that work in different places and, although the name of the thesis suggests, that are references from cultural institutions and cases from around the world. Lastly, we have drawn the main pain points of the visitors that we could observe from our experience working in museums -- at the Museum of Contemporary Art from University of Sao Paulo (Brazil, between 2014 and 2017) and at the Ashmolean Museum (Oxford, in 2018). 
Table 1: Main pain points of visitors in the museum experiences

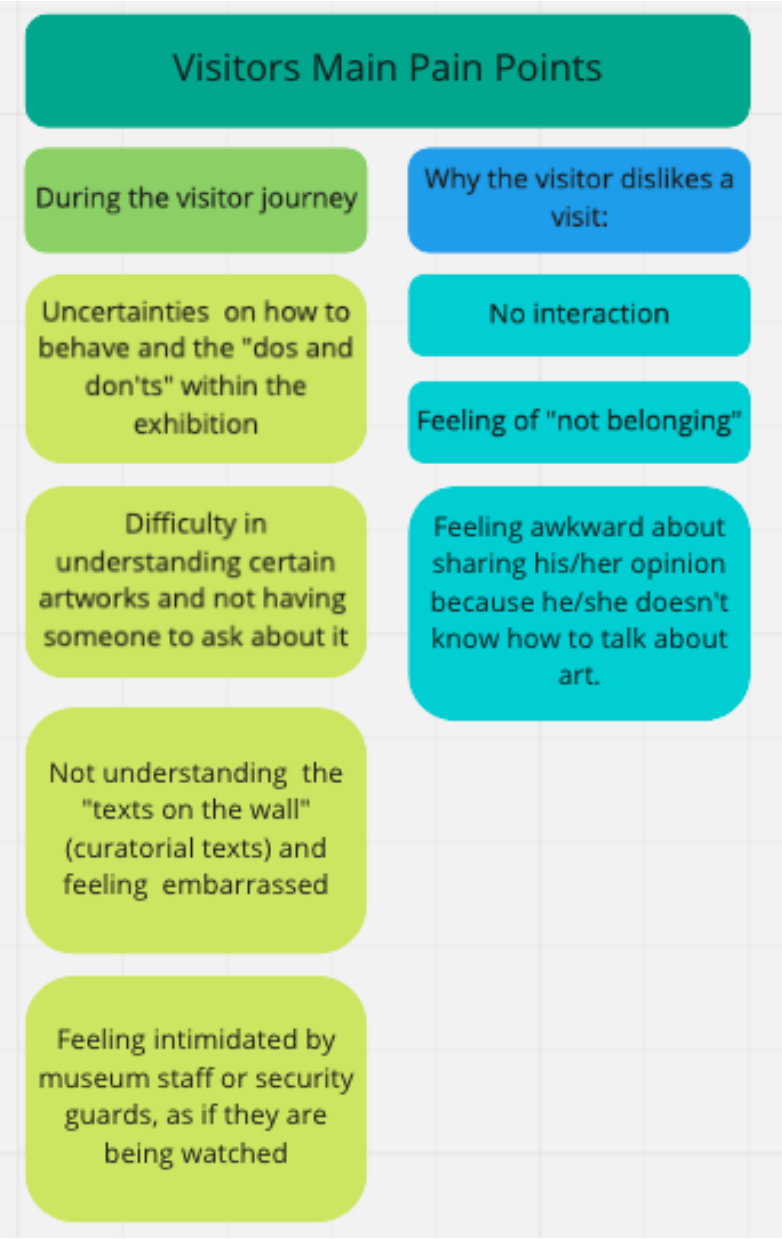

Since we had a few trends, we prioritised the main pain points based on the concepts of participatory museums that we could impact directly with our project.

\section{METHODOLOGY AND RESULTS}

As we understand that what people say is different from what they do, we chose to build a clickable prototype to apply a qualitative interview with the participants.

With the interview we aimed to answer:

- If the participant is able use an interface based on listening to the content;

- If the participant is interested in listening to other voices and perspectives whilst experiencing art;

- If they are interested, what motivated them to choose each audio;

- If they are not interested, why not;

- If people want to participate by recording and sharing their impressions.
Our sample for the first prototype was 11 people, where 4 of them are in England (UK) and 7 of them are in Sao Paulo (Brazil). We opened the interviews to volunteers to participate, ranging from avid museum-goers to casual visitors, with this amount we found the saturation (when increasing the sample doesn't improve the hypothesis) during the interviews to answer our questions about the different voices in the museum.

The duration of the online interviews was from 30 minutes to 1 hour, divided in 2 parts. First part was an "usability test" with a moderator, second part regards to questions and a card sorting exercise. However, our goal wasn't an usability test, we first wanted to understand the viability of the audio tool for the public and then invite them to index the available audios.

For this phase of the process, we invited a few people to create audio recordings for the artwork we selected for the prototype. This way we aimed to generate content that could be found in a real world scenario. We also added audio descriptions that were adapted from the museum text in which the artwork is on display. The "chat with a curator" audio was inspired by academic text about the artwork. The opinion of the children (the girl in Brazil, the boy in the UK), the teenager (in Brazil) and the adult (in the UK) audios were spontaneous and recorded once, prompted by the direct question "What do you feel when you see it?". The transcriptions were made by the authors, in order to make the experience as accessible to the participants as possible, giving them full autonomy to navigate between audio and transcribed text if they wished to do so.

\section{Start exploring by choosing one}
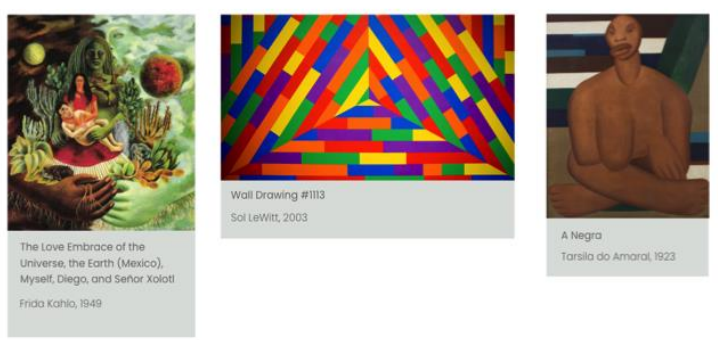

Figure 1: Home screen of the prototype with the 3 paintings (from left to the right) Frida Kahlo, Sol LeWitt and Tarsila do Amaral.

The selection of the artists is not relevant for this paper, what it's important is how the participants relate to them. We chose paintings with abstraction and figures, to understand the difference of relation as well. 
In the first part of the interview, they received the link of the prototype and shared their screen with the moderator. They chose one of them and they have time to navigate in all of them. All the screens had the audio description of the painting, the audio of 2 or 3 different people and they had a chance to read the audio, with the audio transcription, while they listened to the audio.
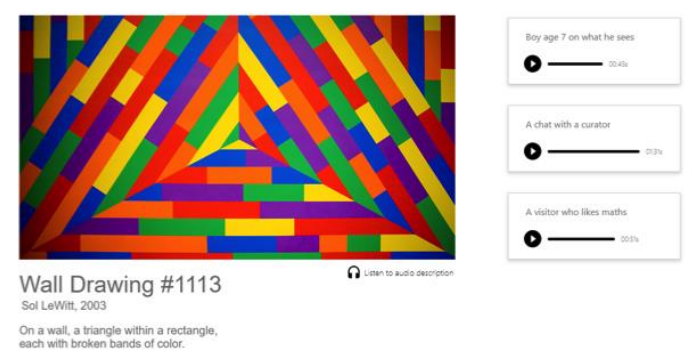

Figure 2: Screen of the painting, clickable prototype.

The prototype was built using Adobe XD, with clear and direct content to facilitate the navigation. To check the interface attended to the accessibility guidelines for colorblind version and contrast for sightless possible participants, we used Stark.
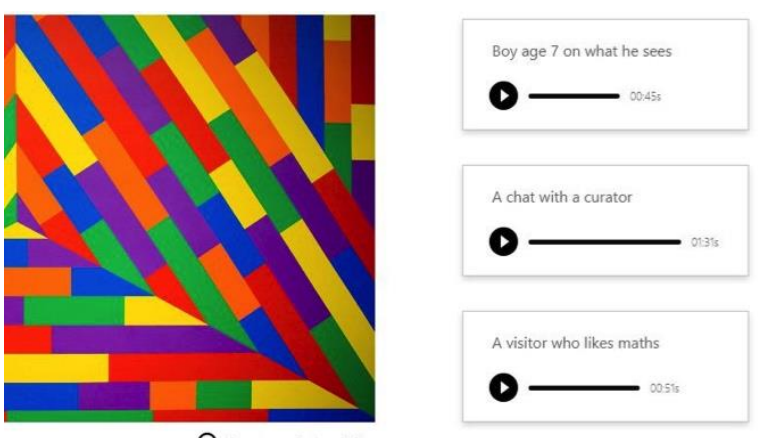

Figure 3: Detail of the screen. Focus on the audio description and readable players.

Because of the time constraint for some of the participants, we had 2 types of interviews. For those who had 30 minutes available, they were offered just one option on the screen (one painting) and they didn't have time to participate in the card sorting, just to answer the questions. The second type, with 1 hour duration, was the full interview.

Title of audios in English and Portuguese versions:

- 7 years old boy on what he sees / 11 years old girl on what she sees

- A chat with a curator / A chat with a curator

- A visitor who likes maths / Teen student

We wanted to offer a glimpse of what to expect in which audio by the title of it, as well as offering the duration of the audio. Whilst the title served its purpose, the audio duration had no impact, or was even noticed by the participants.

The card sorting also had the goal to engage the participants in a more embodied participation, even if in the mediated virtual scenario due to the social distancing circumstances.

\subsection{Results about listening}

All the participants listened to the audios intuitively. Almost half of them wanted to listen and read the content mostly because of the Curator audio, which they found the vocabulary challenging to understand. For the other audios they could just listen to. There was one interviewee who didn't want to listen, but when she read the child's opinion she listened to the audio because she wanted to "hear her voice". This result is very important for the continuity of the prototype because it proves 2 points: people use audio and they're interested to listen to other voices about the artwork. The highlights of the reasons of the audio tool are:

(i) They can see the artwork and listen at the same time, which improves the fruition.

(ii) It's accessible for those who have sightless symptoms and reduced mobility (when they have to read long texts on the walls).

(iii) It can achieve a sensitive layer because of the voices, the pauses, that it's not usually the main goal of the written text.

\subsection{Results about diversity}

All the interviewees affirmed that it was interesting to listen to other voices besides the usual curatorial content. Highlights of the interviews:

(i) The majority of the interviewees stated the importance of the other voices presented in the artwork.

(ii) Most of them mentioned the children's audios as a pleasant surprise, connecting the experience of the listening with sentences as "expressive or imaginative", "opened my mind", "pure feeling", "I let myself imaginate with him/her".

(iii) $45 \%$ of them listened to the audio description. Although, all of them listened just once, they mentioned how that helped to expand the vision of the artwork

(iv) $54 \%$ of them felt comfortable sharing their impressions about artwork because of the difference of the audios, it made them perceive their opinion valuable as well. 
The audio of the children had the most positive results on the participants, generating dialogue, vulnerability and joy on the participants. The interviewees in England and in Brazil unanimously enjoyed the audio by the 7 years old boy/ 11 years old girl. For them it was a new perspective to listen to a child, even when a few participants initially thought nothing could be gained from that. Even though the children had different approaches to the artworks, the results were very similar for the participants, stimulating imagination and the perspective based on sentiments, not analysis.

Still, in the card sorting phase, we could notice that if they hadn't listened to the children's audio, they wouldn't have chosen the \#ChildrenOnArt card as an option. So, the experience they had with the children's opinion is extremely relevant, but it ranks low in their choice possibilities if they have more options and less time, and this is a challenge to be solved with the indexation as we explain later on.

\subsection{Results in participation and index}

As this projects aims to build a tool that gives space to the audios offered by the institution in which the tool will be contextualised to, as well as open to the submission of the audience that desires to do so in the same level, it is fundamental in its design and conception to find a mechanism of indexation.

For this step of the research, we wanted to work together with the participants using strategies of participatory design. At first, we thought that the internet mediation could be a barrier, instead, we testified that online screens worked as a potencial. Because they have all the tools in hand in their own computer and they have no emotional attachment to any person of the audio, we confirmed Simon's statement that people feel more comfortable both breaking each other's opinion and collaborating with strangers, "in this way, technology that looks like a social barrier leads instead to social engagement" (2010, pp.97). After the experience of listening, the interviewees could exercise their participation using card sorting.

The board was prefilled with a few suggestions to assist the participants to acclimatise to the exercise. They could rank the existing tags in the columns (Like, Dislike, Irrelevant), and they could also suggest new tags.

The first noticeable thing was that some of the proposed tags were deemed irrelevant by the majority of participants, such as "Why I love it" or "Why I hate it"; especially the latter was quickly dismissed. The participants stated that opinions tagged in these groups seemed shallow or passionate, they'd prefer to listen to groups that weren't obvious. The tag \#ArtWorldGossip divided opinions, despite the fact that initially is relevant, the content they aimed to see is more connected with a "fun fact" about the art universe, not exactly a gossip. So, the participants that chose \#ArtWorldGossip, the minute later, gave an option similar to \#FunFact, meaning the same sort of content.

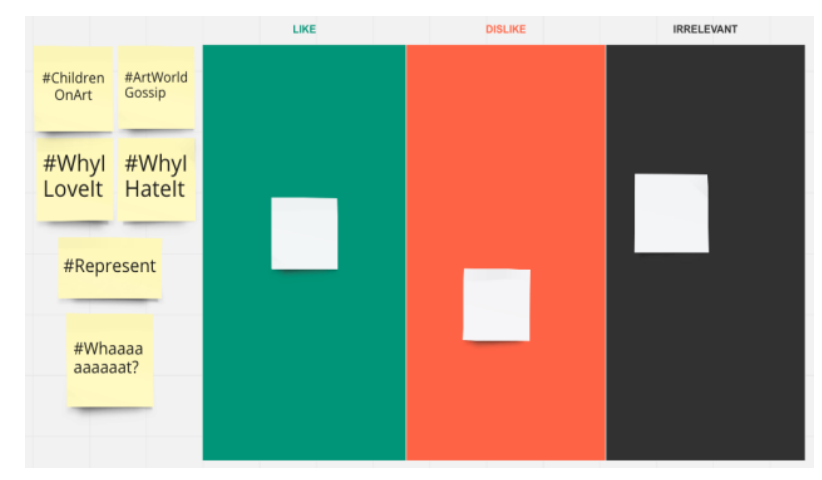

Figure 4: Board of card sorting in the beginning of the exercise.

The participants chose the tags that could potentially group the content they'd like to hear and they could write and suggest others. We extracted the most likeable and desirable with the rank below:

1. \#ChildrenOnArt

2. \#Whaaaaaaaat?

3. \#ArtistsOnArt - created by the participants

4. \#FunFacts - created by the participants

5. \#Represent

All participants were also asked to list keywords, feelings or impressions about the audios they listened to. With this exercise, we aimed to identify common groupings that could also be used to create possible tags for the index system.

Based on these findings, we can suggest that each audio is indexed by 3 tags. The goal is that each tag will be attractive to a user-visitor, but it won't be limited to the audio creator to be strictly put in one category.

In this way, the goal is to open the visitors to voices they wouldn't otherwise listen to, but that would still be a satisfactory experience once they did.

In the case of children, for example, a few participants actively sought those perspectives for the novelty, but some wouldn't have outside of the experiment knowing it was a child. However, if that audio is grouped under another tag, such as 'pure feeling ' or 'free thinker', it would bring forward the audio in the same level as an artist that shared a similarly indexed impression. 


\subsection{Identity as a motivator}

One of the hypotheses raised during the initial phases was that visitors would feel inclined to participate if they could see themselves and the opinions and impressions already shared. Would questions of age, professions, race, and other Identities be a marker for them? What was found, as John Falk (2016) states, visitors change their motivations according to their assumed identity of that moment, in that case, if they are explorers or learners, for example. It was found amongst the interviews conducted in England, that the audio titled 'visitors who likes maths' attracted the interviewees based on them projecting themselves in the visitor role, relating that they imagined the speaker to be in their same age range, or profession (as an engineer) and that attracted them to that audio track.

In addition, it was noticed that the concept of identity cannot be related just to representation itself, understood here exclusively by markers of gender, race, age and direct classifications. During the interviews it was evident that the contrast of the opinions was sine qua non for generating a friendly environment for the audience. It's known that traditional curatorial texts sometimes separates the audience from the museums, still, when the same content is provided together along contrasting points of views, this wall fell, because of the contrast of the information. Even though this information presented doesn't represent the audience's, the variety of opinions opens space for the audience to feel encouraged to bring theirs to the same level. When the tool is able to celebrate and share the singularity of the people horizontally, the collective environment feels safe to be part of it.

\section{REFLECTIONS}

Museums biggest competitors for audiences are not other museums, but sources of entertainment and content, especially online. Opening up the possibility of participation via audio submissions from the audience to share their impression is a must, and valuing the product of that participation by adding it to the same level as content created or commissioned attends Jenkin's participation guidelines. However, the research found that a curatorial process to the audios submitted by the audience also ensures the quality of them, and delivers a better fit to the expectation of the visitoruser. In one of our examples, we had an audio entitled a "visitor who likes maths", as a signal to a personality trait of the visitor with aims to forge a connection to the listener. Although, what was found is that the expectation to learn about maths in connection to the artwork was not met at that time. Even if the title was successful in attracting the user's attention at first. It was useful, nonetheless, to highlight a desire to listen to perspectives from specific job roles that are not directly connected to the art world, but can still offer a fresh perspective.

Communication at the museum (online or onsite) is based on written texts. When we subvert this logic, offering first the listening to the visitor, we are able to conduct people to a different layer of sensitivity, disorganizing the common sense in that place offering the audio and different options of information of an artwork. As Rússio presented in her studies during $80^{\prime}$ in Brazil (Carvalho \& Escudero 2020), the importance of identity and memories of the visitor is as important as the art that has been shown. Moreover, the audio tool emerges to surface opinions that, generally, are not together, this variable connects the visitors to different identities, allowing them to bring their own voice into the spotlight, if it is desirable for them, because the visitors come into the exhibitions "wellformed interests, knowledge, opinions, and museum-going experiences" (FALK 2006, pp. 153). The choice of audio is endorsed by the habits, we used the support of transcriptions, though. As the audio descriptions, as well. According to the Brazilian company Deficiência Tech (Disability Tech), specialised in accessible technology, it's important to amplify the habits that are not usually endorsed. Furthermore, this aspect goes beyond accessibility, because the tools could provide a different perspective, new poethicals, for those who have the sense of sight but let her/himself navigate through the words of audio description. The importance of the mutant aspect of the index and the possibility of adding a new impression is that everyone could increase the system with her/his world of the artwork we don't say to the person what to see, but a person can say to us.

\section{FINAL CONSIDERATIONS}

It was not our goal to find a definitive, such as BYOD (Bring your own device) or a full onside installation to the device, at this stage. For us, the importance of this investigation was to understand what creates engagement and connection to the audience through inviting them to be part early in the design process, and we found that it can even be applied to both physical or online spaces, in varied formats. What is meaningful in this process is to understand a few guidelines:

- Co-design to find a common denominator in the creation of tags;

- Index varied voices, both commissioned and spontaneously generated, under three tags that can appeal to different, nonrepresentative, identities of the users; 
- The use of the three different tags allows the content to be seen from different takes, showing the complexity of the opinions and attracting new listeners;

- The availability for users to submit their audio impressions, even if not all will do;

- A content curation for quality assurance;

- Allow visitors to suggest what sort of tagging group interest them (professions, age, what was happening in the world at that time);

- Use the suggested tags to invite specific voices to create content, but displaying it at the same level as spontaneous submissions.

This investigation indicated to us the need for a deeper layer of the study to be conducted. Nevertheless, the relevance of sharing this result lies in the importance of participation since the first steps. Without these findings, the complexity of understanding the identity and the challenge of the indexation of the "most engaging opinion $x$ lowest clickable opinion" wouldn't be possible.

The 3 tags indexation system is fundamental to challenge the habit of amalgamation of opinions, such as "all the children's opinions are the same" or "curatorial audios are dull". When the tool crossindex tags, we can offer a more complex opinion such as "a child (tag 1) that has a super imaginative opinion (tag 2) about a fun fact (tag 3) she heard at school". This indexation mechanism, besides categorizing the shared impression more accurately, can reach a visitor that otherwise wouldn't have clicked it spontaneously.

\section{REFERENCES}

Carvalho, L.; Escudero, S. (orgs) (2020) Latin American Museological Theory. Fundamental Papers. Series Editor: Olga Nazor, ICOM-ICOFOM.

Falk, J. (2006) An Identity-Centered Approach to Understanding Museum Learning. Curator: The Museum Journal, California: Wiley-Blackwell

Falk, J. (2016) Identity and the museum: visitor experience. Nova York: Routledge.

ICOM (2020) Dados para navegar em meio às incertezas: Parte II - resultados da pesquisa com públicos de museu. ICOM Brasil.

Jenkins, H. (2009) Confronting the Challenges of Participatory Culture: Media Education for the 21st Century. MacArthur Foundation, MIT Press.

Sarraf. V. (2013) Communication of the five senses in Brazilian cultural space: strategies of mediation and accessibility for people with their differences. São Paulo: Pontifícia Universidade Católica de São Paulo.

Schindler, B.; Sopper Jr, E.; Ramírez, G.; Souza, D. (2020) O uso do WhatsApp como ferramenta de Ensino. ILCJ, V.10, n.1.

Simon, N. (2010) The Participatory Museum. California: Museum 2.0 Press.

Tallon, L. (2008) Introduction: Mobile, Digital, and Personal. In: Tallon, L; Walker, K. Digital Technologies and the Museum Experience. Plymouth: Altamira Press. 